particularly of prehistoric times, is of less importance to the student than the geography of the world as it is to-day. The geographer can make a definite contribution to the solution of many urgent problems of the day in colonisation, trade, transport and agriculture. Scientific surveys of every aspect of man's environment are much needed and the basis of all this work must be an adequate map. Prof. Mason urged that the appointment of a trained geographical adviser in the government of any country would be invaluable in its development and control.

\section{Lord Bledisloe's Cawthron Lecture}

New Zealand is singularly fortunate in having in its Governor-General, Lord Bledisloe, a keen and distinguished agriculturist, thus representing in the highest governing and administrative circles one of the most important industries of the Dominion. On October 3, Lord Bledisloe delivered at Nelson the annual Cawthron lecture, his address being entitled "A Conspectus of Recent Agricultural Research with Some Reflections Thereon". This is the first time that a Governor-General of a Dominion has delivered within it the chief scientific oration of the year, and as one would have expected, in collating the agricultural research of the past three years, as Lord Bledisloe did in the lecture, the economic importance of agricultural research has been emphasised from an essentially broad though authoritative point of view, thus taking into consideration not only the British Empire, but also other countries. The amount of detailed facts, with commentaries, concerning agriculture which have been assembled into this lecture is scarcely short of amazing. Lord Bledisloe has left no stone unturned in his search for data. Every aspect of agricultural and horticultural research is reviewed and there is scarcely a research department; institute or station within the British Empire which is not considered and its recent work discussed. Other countries outside the Empire, such as Denmark, Germany, the United States, Holland, Finland and others, have been combed for results and duly considered. Apart from the general consideration of horticulture, arable and dairy farming and apiculture, and their more detailed aspects such as the study of the constitution of wool, vitamins, etc., researches in connexion with more specialised Empire products such as sugar and tobacco are also reviewed. The lecture has now been published and may be obtained from Messrs. Whitcombe and Tombs, 3 Addle Hill, London, E.C.4, price $1 s$.

\section{Expansion of the Universe}

At the Friday evening discourse on November 25 at the Royal Institution, Dr. Knox-Shaw discussed the observational evidence for the expansion of the universe. The nebulæ lying beyond our galaxy stretch away into space farther than our present limit of penetration. Most of them can be studied only with our largest telescopes, and for our know. ledge of their distances and motions we are indebted largely to the work of Dr. Hubble at the Mount
Wilson Observatory. In some forty nebulæ he has been able to detect individual stars, and in a few cases to identify them as belonging to types already known in the galaxy. From the apparent luminosities of these stars he has derived distances for the nebulæ in which they are involved. In all other cases the distances are based on the apparent brightness of the nebulæ themselves. The scale of distance thus constructed is still very uncertain. The absorption lines in the spectra of the extra-galactic nebulæ are shifted towards the red in a way that suggests that they are all moving away from us with velocities which increase with the distance. Whether there is an alternative explanation of these shifts is a question for the physicist rather than for the practical astronomer, but if we assume that they actually indicate motions of recession, we find that the velocities of the nebulæ are proportional to their distances from us, as would be required in a uniformly expanding universe. Hubble's value for the rate of expansion, an increase of $560 \mathrm{~km}$. a second for each million parsecs of distance, must be regarded as liable to revision as further observational material becomes available. A cluster of very faint nebulæ in Gemini, so remote that its light has taken some $135,000,000$ years to reach us, has recently been photographed at Mount Wilson, and seems to be moving away from us at the immense speed of 24,000 km. a second.

\section{Slaughter-Houses in Great Britain}

THE eleventh Benjamin Ward Richardson memorial lecture was delivered, under the chairmanship of Sir James Crichton-Browne, before the Model Abattoir Society on November 30 by Mr. T. Topping, who chose for his title "The Slaughter-House Problem:". He commenced by saying that had local authorities more generally carried out the advice given by Richardson when he founded the Model Abattoir Society fifty years age, there would have been no slaughter-house problem to-day, and there would have been greater benefit for other public health protective measures. As it is, there is a very real problem owing to the fact that the slaughterhouse provisions of the Act of 1847 are still the principal law on the subject to-day. No advance was made by the Public Health Act of 1875, so that many buildings quite unsuitable for the purpose came into existence as private slaughter-houses. The Rural District Council (Slaughter Houses) Order of 1924 gave State recognition to and largely increased the capital value of hundreds of unsuitable buildings that had been erected as slaughter-houses prior to the order. Thus for nearly sixty years, most local authorities steadily increased the financial difficulties of providing for the only effective means of supervision of slaughter-houses and of securing hygienic preparation of carcase meat. According to Mr. Topping, there are only about 110 slaughterhouses in Great Britain where the buildings and arrangements are satisfactory, whereas in a large percentage, complete supervision and inspection is extremely difficult if not impossible. As a solution of the problem, he suggested first that the Ministry

No. 3293, Vol. 130] 